\title{
Survivors at risk: Hodgkin lymphoma survivors at high risk of second
}

\section{cancers}

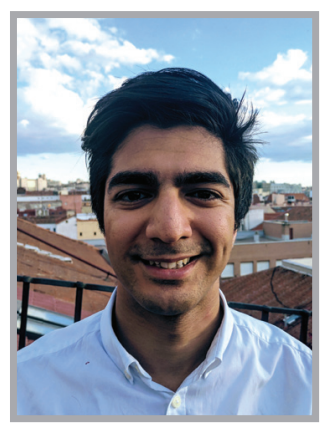

Amit Sud* speaks to Sebastian Dennis-Beron, Commissioning Editor:

Amit Sud is a clinical research fellow in Hematology at the Institute of Cancer Research, UK. He undertook his undergraduate medical training at the University of Manchester, gaining an honors degree. He completed his Masters in Medical Research at Manchester University, gaining a distinction. He continued his medical training in Manchester and London and started his specialization in Hematology in South West London. He was successful in obtaining a Cancer Research UK funded clinical research fellowship in Hematology under the supervision of Professor Richard Houlston at the Institute of Cancer Research. His current research focus is that of genetic susceptibility to Hodgkin lymphoma. He is a trainee member of the NCRI Lymphoma Clinical Studies Group.

First draft submitted: 21 March 2017; Accepted for publication: 30 March 2017; Published online: 30 June 2017

\section{Q Could you please provide a brief summary of your career to date?}

I completed my undergraduate medical training at Manchester University (Manchester, $\mathrm{UK}$ ) and also spent an extra year undertaking a masters in medical research. After this, I continued my medical training in Manchester. I moved to London to continue my general medical training and, then commenced my hematology specialist training here at the Royal Marsden and the Institute of Cancer Research, London, UK. Two years ago, I began a PhD funded by Cancer Research UK at the Institute of Cancer Research (London, UK), supervised by Professor Richard Houlston.

\section{Q What is your research focusing on at present?}

My research looks specifically at genetic susceptibility to Hodgkin lymphoma, which is a particular malignancy I am interested in, as well as other B-cell tumors. I utilize genetic, epidemiological and biological data with my aim is to try and understand Hodgkin lymphoma in further detail.

Q You were an author on a recent study demonstrating that Hodgkin lymphoma survivors are at high risk of secondary cancers: could you give our readers an outline of the study \& its methodology?

Hodgkin lymphoma was one of the first cancers that the medical profession managed to obtain relatively high cure rates through treatment involving chemotherapy and radiotherapy [1]. What became apparent is that many patients who survived the Hodgkin lymphoma had a lot of long-term significant complications such as second cancers and cardiovascular disease [2]. So over the past few decades, there have been a lot of studies

*Division of Genetics and Epidemiology, The Institute of Cancer Research, London, SW7 3RP, UK Amit.Sud@icr.ac.uk 
trying to investigate the risk factors of developing these complications.

In terms of second cancers, the excess risk observed in Hodgkin lymphoma survivors has been reported to be influenced by various factors including age of treatment, site and dose of radiotherapy, chemotherapy and smoking [3-10]. So what has been postulated, although not demonstrated through epidemiological studies, is the detailed impact of family history on the second cancer risk. So in collaboration with Lund University (Lund, Sweden) and the Deutsches Krebsforschungzentrum (Heidelberg, Germany), we were able to use the Swedish cancer family project database [11], to identify all Hodgkin lymphoma cases diagnosed between 1965 and 2012 and their relatives. This permitted us to identify which patients developed a second cancer and also to determine family relationships between the individuals. This allows for calculation, in an unbiased manner, of the risk of second cancer in individuals with Hodgkin lymphoma. That is calculated using the 'standardized incidence ratio' that takes into account background population rates of cancer, age and sex match.

We were then able to investigate the influence of a family history of cancer and concordant cancers. Therefore, if an individual has a relative with for example, lung cancer, what is the individual's risk of developing lung cancer after getting Hodgkin lymphoma? We also used epidemiological tools, such as estimating cumulative incidence with competing risk, and relative survival, to understand the second cancer risk in individuals with Hodgkin lymphoma [12].

Q What roles did familial history of cancer \& radiotherapy during treatment of cancer have on the risk of developing secondary cancers, respectively?

Unfortunately we did not have data on treatment, so the study could not address an interaction between say the specific type of treatment and the family history.

However, our study examines the broad picture of second cancer risks in Hodgkin lymphoma patients. With regard to the influence of family history, our study shows that there is a 1.3-fold higher risk of a second cancer in Hodgkin lymphoma patients who have a family history of cancer compared with those without a family history. That relationship is correlated with the number of first-degree relatives affected. What I mean by that is, the great the number of first-degree relatives with cancer, the greater the risk of second cancer after Hodgkin lymphoma.

With respect to the concordant cancer risk; there is a 3.3-, 2.1- and 1.8-fold increased risk of developing lung, colorectal and breast cancer, respectively, in Hodgkin lymphoma patients who have a family history compared with those who do not have a family history of this specific cancer. The other interesting point is trying to understand the relative contribution of different risk factors. First, the familial risk of developing lung cancer in the general population, second the risk of Hodgkin lymphoma patients developing lung cancer and third, the risk of Hodgkin lymphoma patients who have a family history of lung cancer, developing lung cancer. That allows one to investigate the contributions of these different components to the overall risk, and the paper demonstrates a greater than additive interaction between family history of lung cancer and Hodgkin lymphoma treatment. The greater than additive risk could be related to other risk factors such as smoking.

\section{Q Were there discrepancies in the risk of secondary cancer due to age or gender?}

This is not a new finding; there have been quite a few publications previously looking at this, but age and sex do influence second cancer risk. Quite a striking example of this, is the risk of breast cancer.

In women diagnosed with Hodgkin lymphoma under the age of 35 years, the risk of developing breast cancer is six-times greater than that of the general population. This contrasts with women diagnosed with Hodgkin lymphoma greater than 35 years where the risk of breast cancer does not appear to be elevated when compared with the general population.

Q How could the results of the study lead to developments in preventative treatments for Hodgkin lymphoma survivors?

Currently, there are screening initiatives in place. For example in the UK, young women diagnosed with Hodgkin lymphoma undergoing mantle field radiotherapy do get screening for secondary breast cancer [13].

The article does not specifically address this, but it may be the first evidence to suggest that there are individuals with a family history of cancer, who we can identify at high risk of developing a second cancer and who may benefit from screening. 
Over the decades there has been a move to use less radiotherapy and less chemotherapy when treating Hodgkin lymphoma patients, and now the approach used is a risk-adapted approach [14]. This means that when someone is diagnosed with Hodgkin lymphoma, the medical team looks at the risk of the disease not being cured and the treatment is tailored based on that risk. So this information could possibly be used to help inform the risk-adapted approach being used currently.

\section{Q Moreover, what clinical impact do you} think this research may have in terms of follow-up for patients once in remission? Hodgkin lymphoma patients are treated by an oncologist or hematologist and are discharged from clinic less than 5 years following treatment. What we know is that a lot of the complications of treatment occur after this 5-year period.

I think it is known but it is important to emphasize that these individuals do have longterm complications that other health professionals need to be aware of. Because they might not necessarily go back to their oncologist 10, 20 years down the line with a problem, other practitioners such as general practitioners should be aware of this second cancer risk, and when they see these patients.

I think there are moves to improve communication between the various levels of care, certainly in clinics that I work in. When patients are discharged from clinics, a summary of care and some information is sent back to the general practitioner.

Q What are the next steps for the field of hematological oncology, given this new development?

It is important to investigate the interaction between family history and other risk factors for second cancer following Hodgkin lymphoma.. This requires long-term follow-up data, good phenotype data and robust collection of data.

Assessing the efficacy of screening in these individuals is also important. Finally, it would be interesting to try and understand the biological basis behind the increased risk in individuals with a family history. It could be environmental, for example, smoking or it could be genetic. It is possible that there is variation within people's genetic code that increases people's risk of developing second cancer after having chemotherapy and radiotherapy, which I think would be an interesting area to explore [15].
Q Do you think more needs to be done to make patients more aware of that secondary risk or is this being done already?

From the medical practice I have observed, this is being done. I think it is very difficult for individuals with Hodgkin lymphoma because when they are diagnosed with Hodgkin lymphoma, the priority for patients is to cure the cancer. It is difficult to think 20, 30 years later and I guess that is one of the important roles of the oncologist; as a guardian for the patient, to make sure the patient understands the late risks of treatment. This can be a very difficult topic to discuss.

Generally speaking, the research community is studying this realizing that this is an important topic that warrants further research and further intervention to try and reduce the second cancer incidence and improve outcomes for our patients. Certainly, for a lot of the cancers, lung, colorectal and breast cancer, survival is stage dependent, so trying to pick these up earlier, will hopefully improve survival of our patients with Hodgkin lymphoma.

Q As cure rates for cancers improve, will there be more of a focus on long-term survivor health for the oncology field as a whole?

I think that is the case, with many clinics now devoted to caring for long-term complications of cancer treatments. Furthermore, there are now established research programs that are examining long-term second cancer risk and other risks such as cardiovascular risk complications and psychological complications that patients experience long after their treatment.

\section{Q What do you hope to achieve in the next few years?}

My interest is in genetic susceptibility and I hope to identify some new genetic factors that influence people's risk of developing Hodgkin lymphoma. I hope to try and provide some biological insight into how genetic risk factors mediate their effects.

\section{Closing statement}

I would like to say that I am very grateful to the collaboration we have established among the three institutes, which has allowed me as a scientist to try and answer an important question. I think it is a good example of a collaboration that has resulted in something that will 
hopefully benefit people. I would also like to thank the patients and individuals who have contributed samples and data to my research.

\section{Financial \& competing interests disclosure}

Amit Sud is supported by a clinical fellowship from Cancer Research UK. The research project discussed in this interview was supported by the German Cancer Aid, the Swedish Research Council, FORTE, and an ALF project grant, Region Skane/Lund University, Sweden. The author has no other relevant affiliationsor financial involvement with any organization or entity with a financial interest in or financial conflict with the subject matter or materials discussed in the manuscript apart from those disclosed.
No writing assistance was utilized in the production of this manuscript.

\section{Disclaimer}

The opinions expressed in this interview are those of the interviewee and do not necessarily reflect the views of Future Medicine Ltd

\section{Open access}

This article is distributed under the terms of the Creative Commons Attribution License 4.0 which permits any use, distribution, and reproduction in any medium, provided the original author(s) and the source are credited. To view a copy of the license, visit http://creativecommons.org/ licenses/by/4.0/

\section{References}

1 Devita VT Jr, Serpick AA, Carbone PP. Combination chemotherapy in the treatment of advanced Hodgkin's disease. Ann. Intern. Med. 73(6), 881-895 (1970).

2 Aleman BM, Van Den Belt-Dusebout AW, De Bruin ML et al. Late cardiotoxicity after treatment for Hodgkin lymphoma. Blood 109(5), 1878-1886 (2007).

3 Leeuwen FEV, Klokman WJ, Hagenbeek A et al. Second cancer risk following Hodgkin's disease: a 20-year follow-up study. J. Clin. Oncol. 12(2), 312-325 (1994).

4 Swerdlow AJ, Barber JA, Hudson GV et al. Risk of second malignancy after Hodgkin's Disease in a Collaborative British Cohort: the relation to age at treatment. J. Clin. Oncol. 18(3), 498-498 (2000).

5 Leeuwen FEV, Klokman WJ, Veer MBVT et al. Long-term risk of second malignancy in survivors of Hodgkin's Disease treated during adolescence or young adulthood. J. Clin. Oncol. 18(3), 487-487 (2000).
6 Dores GM, Metayer C, Curtis RE et al. Second malignant neoplasms among long-term survivors of Hodgkin's disease: a population-based evaluation over 25 years. $J$. Clin. Oncol. 20(16), 3484-3494 (2002).

$7 \quad \mathrm{Ng}$ AK, Bernardo MV, Weller E et al. Second malignancy after Hodgkin disease treated with radiation therapy with or without chemotherapy: long-term risks and risk factors. Blood 100 (6), 1989-1996 (2002).

8 Hodgson DC, Gilbert ES, Dores GM et al. Long-term solid cancer risk among 5-year survivors of Hodgkin's lymphoma. J. Clin. Oncol. 25(12), 1489-1497 (2007).

9 Swerdlow AJ, Higgins CD, Smith P et al. Second cancer risk after chemotherapy for Hodgkin's lymphoma: a collaborative British cohort study. J. Clin. Oncol. 29(31), 4096-4104 (2011)

10 Van Eggermond AM, Schaapveld M, Lugtenburg PJ et al. Risk of multiple primary malignancies following treatment of Hodgkin lymphoma. Blood 124(3), 319-327; quiz 466 (2014).
11 Hemminki K, Li X, Plna K, Granstrom C, Vaittinen P. The nation-wide Swedish family-cancer database-updated structure and familial rates. Acta Oncol. 40 (6), 772-777 (2001).

12 Sud A, Thomsen H, Sundquist K, Houlston RS, Hemminki K. Risk of second cancer in Hodgkin lymphoma survivors and influence of family history. J. Clin. Oncol. JCO.2016.2070.9709 (2017) (Epub ahead of print).

13 Howell SJ, Searle C, Goode V et al. The UK national breast cancer screening program for survivors of Hodgkin lymphoma detects breast cancer at an early stage. $B r$. J. Cancer 101(4), 582-588 (2009).

14 Johnson P, Federico M, Kirkwood A et al. Adapted treatment guided by interim PET-CT scan in advanced Hodgkin's lymphoma. N. Engl. J. Med. 374(25), 2419-2429 (2016).

15 Ma YP, Van Leeuwen FE, Cooke R et al. FGFR2 genotype and risk of radiationassociated breast cancer in Hodgkin lymphoma. Blood 119(4), 1029-1031 (2012). 